\title{
The Ecological Crisis and the Principle of Relationality in African Philosophy
}

\author{
Mark Omorovie Ikeke \\ Delta State University
}

\begin{abstract}
The way that humans think about the earth certainly affects the way that they relate and behave towards the earth and all its life forms. The various ideologies or worldviews that humanity has experienced such as dualism, capitalism, holism, animism, ubuntu, ukama, vital force, colonialism, and so forth are all different ways of thinking and relating to the earth. The paper argues that dualistic ways of thinking or viewpoints that radically separate the human as distinct from the earth are hostile to both human and earth flourishing. It further argues that the ecological crisis which has witnessed the destruction and pollution of the ecosystems and other devastations cannot be solved when humans continue to see the earth as an object for conquest and exploitation. Using a critical hermeneutics method, the paper affirms that the African principle of relationality can help in mitigating the environmental crisis. It finds and concludes that if this principle is radically practiced, a better environment will be created.
\end{abstract}

Keywords: ecology, relationality, African, philosophy, ubuntu, vital force

\section{Introduction}

Many factors are responsible for the global ecological crisis. Among these factors are people's worldviews and perspectives about nature or the environment. Worldviews that have likely contributed to the global ecological crisis are dualistic, "multiplicity," colonial, and other mindsets that tend to radically separate the human from the natural world, promote human superiority over nature, and place the human as distinctively distinct from nature. While it is true that the human is not the same as nature, yet the human shares much with nature that the human should be seen as one of nature.

The issue of the relationship of the human to nature is the principal preoccupation of this work. The paper theorizes that the mindset of dualism and other related philosophies have contributed to the ecological crisis. It avers that in resolving the environmental crisis, humanity must embrace the African or other indigenous worldview of relationality.

\section{Conceptual Analysis}

The word "relational" has its root in the word, "relate." This word "relate" means, "to show or make a connection between two or more things" (Oxford University Press, 2014). When relational is spoken of, it has to do with connection or link. It implies that things or reality is interconnected. They share in solidarity and oneness. Though things may be distinct, they are not ultimately separate or divided. The term relational is akin

Mark Omorovie Ikeke, Ph.D., Department of Religious Studies and Philosophy, Delta State University, Nigeria; main research field: Environmental Ethics, Ecotheology, Cultural Studies, Human Rights, Indigenous Peoples and Cultures, and Conflicts Resolution. Email: Ikeke7@yahoo.com. 
to the word, "ecosolidarity," a word explained to mean: "The unity and inter-relationality of all cosmic beings... ecosolidarity implies radical and active relationality of all life forms, in which each contributes to the mutual flourishing of others” (Ikeke 2004, 354-5).

African philosophy is critical appraisal and evaluative hermeneutics of African traditional thoughts systems and affairs, and issues of contemporary relevance to Africa's current progress and development. It is concerned with concepts like African medicine, African social systems, the African extended family, Pan-Africanism, questions of ethnicity, development issues, identity issues, and many others. African philosophy has also entered into critical questioning of African Traditional Religion and culture. African philosophy is not restricted to continental Africa. It takes place where there is a critical examination of African affairs from a philosophical vantage point. It can be done by people of African ancestry and by people of other nationalities.

It is from the African cosmic perspective rooted in a religious worldview that sees a divine creator being as creator of all things and that the creative presence of the creator is present in the elements of the universe that the issue of relationality is studied. The study of the African principle of relationality is examined here because of the firm belief that the ecological crisis is partly as a result of inhibiting or distorting views of reality and the human place in the universe.

What then is the ecological crisis? In the first place, the word, ecological has to do with ecology. It is true to state that ecology is:

a word derived from the Greek roots oikos meaning "house”. Ecology is literally the study of "homes" or "environment”... It is the science of biological interactions among individuals, populations, and communities, and also of ecosystems-the inter-relations or biotic communities with their non-living environments. (Bellamy 2007, 144)

For Mackenzie, Ball, and Virdee, "ecology is the study of interactions between organisms and their environment. The 'environment' is a combination of the physical environment (temperature, water availability, etc.) and any influences on an organism exerted by other organisms - the biotic environment” $(1998,1)$.

Both definitions just given reveal that at the heart of ecology is the issue of relationships. Without relationships, ecology or ecosystems cannot be spoken of or written about. Ecology speaks of interactions among the various elements and organisms in the cosmos. These interactions are ones of interdependence, mutuality, networking, and linkages. All aspects of the natural world or ecosystems are important to life in the cosmos. This is why any threat to any form of life aside the ones inbuilt in the food chain of nature endangers nature. This is where the issue of ecological crisis comes in. Humans have overexploited the resources of the ecosystems, degraded the land, destroyed forests, and made life on earth insecure. The ecological crisis refers to the unprecedented massive destruction of life's ecosystems such as the oceans, forests, land, animals, plants, etc., through human activities such as industrialization, urbanization, mechanized agriculture, mass media, entertainments, etc. There is nothing wrong in these human activities in themselves. But the by-product of these activities at times is that humans have massively destroyed forests for more human habitation, raped resources from the earth to feed human industries and these often are done without care for other non-human lives, rather all that matters is economic growth. The environmental crisis as Ignacimuthu argues:

... is constituted by large-scale devastation of the environment, damage to water, air and soil, and to genetic diversity; by destruction of rain forests, extensive soil erosion and desertification; be massive use of pesticides, insecticides, and herbicides which deplete and poison the soil; by the squander and destruction of sea resources, mangrove swamps and 
coral reefs; by anarchic and profligate industrial production and overconsumption as well as overuse and waste of nature's scarce and non-renewable treasures; by the ambiguities of nuclear technology, the horrors of nuclear weaponry, and the hazards of radioactive waste. $(2010,22)$

There is a need to affirm that life-affirming interactions not destructive ones are needed on earth. Human worldviews are helpful in creating these interactions.

\section{Some Worldviews and the Ecological Crisis}

Humanity and the entire earth are facing an unprecedented ecological crisis. In no other epoch has the earth suffered so much than in this epoch. For some especially in Christianity, the earth is simply there for humans to have dominion over. These persons are quick to quote the text of Genesis 1:26 in which God commands humans to have dominion over the earth and its resources. For them, dominion means exploitation and conquest. This is the view of "dominionism" that states that humans are totally higher and above nature; they are to exercise power over nature and nature is there to serve their needs (Vantassel 2009, 2). No wonder the theologian Lynn White critiques Christianity for contributing to the devastation of the earth. Though Christianity has featured such figures as Francis of Assisi, who argues for human friendship and kinship with other creatures, Christianity in its western form is essentially anthropocentric and man is to have dominion over creation and rule over them (White 1967). This according to White has contributed to much industrial exploitation of the earth. But this does not imply that the entire environmental crisis is to be blamed on Christianity. Compared with a tradition such as the catholic tradition that affirms a mystical and sacramental universe, until recently, many Christian cycles have recorded a poor environmental movement because of the ingrained belief that the earth is simply an object at the service of man.

Another worldview that has seriously contributed to the ecological crisis is rugged capitalism. The views of the eco-theologian and philosopher Thomas Berry are helpful here in understanding how capitalism has contributed to the ecological crisis. Critiquing capitalist technology, he shows that industrial processes have produced jobs and profits, expanded life, but they have equally alienated humans from their mystic sensitivities to natural life systems (Berry 1988, 50-54). The capitalist ideology of unlimited economic growth is also a problem. Economic growth in terms of statistics and figures is paraded at the expense of human wellbeing and ecological flourishing. Capitalism is rooted in a spirit of consumerism, individualism, and profiteering. The capitalist free market economy has driven much of the industrial-technological advancement of the present age. But this has not been without its negative effects. Capitalism because of its spirit of free enterprise and competition can inspire rugged individualism. In a society in which rugged individualism is celebrated, many people are likely to live consumerist lifestyles without caring the impact of their lives on others. Success at all cost is glorified no matter the cost. The spirit of sacrifice is often ignored and an extravagant and luxurious lifestyle is promoted.

A dualistic mindset has also contributed to the ecological crisis. One of the vital hindrances to the principle of dynamic relationality in which all things enhances one another is western dualism. The danger of a dualistic mindset is that it has separated humans from the earth or nature. Humans are seen as being here and nature is over there. Humans are perceived to be radically different from the other (nature). Humans are perceived in this dualistic mindset to be masters and controllers. Nature is a thing and object under them. It can be conquered and subdued. This is not to say that it is only a dualistic mindset that produces images of human control of nature. Francis Bacon sees nature as external to humans and a platform for unlimited human accomplishments 
and this idea will inspire "rationalism, mechanism, and patriarchalism" that has helped in destroying nature (Coates 1998, 176).

A fundamental reason why the above ideologies have contributed to the ecological crisis is that they see the human relationship to the earth as that of exploitation. The earth lacks life, and is a mere object. The human that is conscious is placed over and above the earth. Since only humans can think, the earth is simply there to serve humanity. In the capitalist mentality for instance, the land is simply an agent of production. The land is only valuable if it can produce profits for human persons. Unproductive land has no value. The above ideologies suffer from a faulty principle of relationality. This is why this paper is proposing an African understanding of relationality that can contribute to resolving the ecological crisis.

\section{Imperative of the African Principle of Relationality}

In many traditional worldviews, including that of Africa, "all things are related, interdependent, holistic and mystic, just as in an emerging scientific world view of our time” (Ignacimuthu 2010, 33). Relationality is at the core of African cosmology. It permeates all of African understanding of the natural world, humanity, the ecosystems, and life beyond the present life. Human life is connected to the ancestral world and linked with God, gods, divinities, spirits, and other forces in the universe. Without relationship of interaction among the various things, persons, and beings in the universe, there is no life. Life will be stagnant, immobile, and inert. No life or being exists without being related to other beings and realities. Mulago states that things in the universe are "inter-related" and in the flow of life, they are relational and this applies to all of reality (Oborji $2005,43)$. The concept of relationality is partly expressed by the fact of holism. This term "refers to a state of complex interdependency, in which each part of an organism has a function” (Turaki 2006, 32). Citing Steyne, he writes that the term holism means:

The world interacts with itself. The sky, the spirits, the earth, the physical world, the living, and the deceased all act, interact, and react in consort. One works on the other and one part can't exist nor be explained without the other. The universe, the spirit world, and man are all part of the same fabric. Each needs the other to activate it. (Turaki 2006, 32)

Bediako as cited by Turaki writes that: "Man lives in a sacramental universe where there is no sharp dichotomy between the physical and the spiritual. The spiritual acts as a vehicle for spiritual power whilst the physical realm is held to be patterned on the model of the spiritual world beyond” (Turaki 2006, 32).

The African perception of the interpenetration of the spiritual and the physical realms does not mean there is no distinction between them. It will not be true to say that the African does not make a distinction between things as some scholars opines. All things are not the same but they share in intrinsic unity and oneness. The natural world is not homogenous. There are aspects of nature that are considered more sacred than others. The vital force that inheres in things is not same all over. Some things in nature carry a higher vital force than others. Ehusani is right to note that "metaphysical and anthropological dualism” permeates western philosophy, western science, and even theology (Ehusani 1991, 219). For the African, all of nature intersect and interpenetrate, all reality is religious, and the entire universe is an integral whole (Ehusani 1991, 220). It is imperative to realize that in African cosmogony,

... the visible and the invisible, these are not two separate and independent entities. They are aspects of one and the same reality comprising basically, the heavens and heavenly bodies of the invisible world and creatures of the visible world down below. The basis of interconnection and interrelation between these two realms is their participation in the Supreme Vital Force of the creator in which every creature shares according to their kind, thereby forming a dynamic and 
ontological relationship among creatures-inter-being. (Ejeh 2008, 211)

In the African cosmos, everything or being exists to enhance or enrich the vital force of other beings. No being exists on its own or for its own sake. The idea of vital force was highlighted by Placid Tempels, a Belgian missionary who worked in Central Africa. According to Tempels, the concept of vital force is central to the Bantu people and this implies that: "The universe is a composite of divine, spirit, human, animate and inanimate elements, hierarchically perceived, but directly related and always interacting with each other" (Oborji 2005, 38). The concern of this paper is not with what name to call that phenomenon. It can be described by various names such as “African panpsychism” (Ikeke 2014), "theistic panpsychism” (Dukor 2010, 61), animistic element, etc. The concern here is with the relationship that exists among things not what is present or seen in them.

It is right to note that in the African traditional understanding, "the human person is at the very centre of existence. The created world and the spirits are there for the service and realization of meaningful life for the human person. Africans see everything else in its relation to this central position of promoting life of the human person” (Oborji 2005, 37). It does not mean that humans are free to devalue or abuse nature.

A universe without interaction will be no universe. Relationality in the universe is expressed in various ways. In the human society, it is expressed through communal living, rites of passage, communal training of children, etc. Among humans and other beings in the universe, it is expressed through prayers, sacrifices, libation and offering to the divinities, ancestral festivals, totemic practices, and reverence for nature. Whatever is done in an African community such as naming ceremonies, celebration of marriages, and funeral events, community labours are all occasions in which people gather together to foster solidarity and unity in the society. The following words of Chinua Achebe are appropriate here: “A man who calls his kinsmen to a feast does not do so to save them from starving. They all have food in their homes. When we gather together in the moonlit village ground, it is not because of the moon. Every man can see it in his own compound. We come together because it is good for kinsmen to do so" (Achebe 1958, 155). Interpreting the above statement of Achebe, it should be realized that: "The African values community living not only because 'it is good for kinsmen to do so,' but because life is his or her ultimate concern and that life can only grow in relationships. Outside the community, there is no life" (Ehusani 1991, 221). Relationship is at the heart of African culture.

In discussing relationship and relationality, it is difficult not to mention the African extended family system. This is a practical expression of social relationality. In the African family system, the family is not just the nuclear family as understood in the western world. The family embraces all the people from a common ancestral root. This includes in-laws, uncles, nephews, cousins, and even distant relatives. At all events in Africa, you see people from the extended family in attendance and they share life together. When harm or disaster happens to an extended family member, the rest members come to the help of the needy family member. These are all expressions of relationality.

Ignacimuthu has forcefully enunciated that:

All life ultimately is interconnected... If even a small fraction of the environment is abused, there is a sense in which the whole of creation suffers. Our impact on the environment is strongly affected by how we view our earthly home. In other words, how we perceive the environment around us will influence how we treat it. $(2010,18)$

This is why it is affirmed in this paper that part of what is inhibiting a true understanding of the human relationship with the earth are various worldviews that have been studied above. Humans are not independent 
of the environment or nature that surrounds them. In African traditional thought, it is believed that if humans do not perform their duties towards nature such as the offering of sacrifices, nature will not yield its fruits for humans. Kinship is not only with fellow humans.

The African perceives that he is in kinship with the earth and the entire cosmos. Both Ubuntu (I am because we are) and Ukama (I am because of the cosmos) are African ideas that explain further this kinship. Forster states that:

Relationships are central to the formation, expression, and understanding of who an individual person is. The African philosophy of ubuntu, more accurately expressed as umuntu ngumuntu ngabantu (a person is a person through other persons), affirms the critical understanding that identity arises out of inter-subjective interactions between persons. (Forster 2010, 243)

Arguing elsewhere Forster is of the opinion that the African worldview mitigates radical western dualism and the Descartes idea of corgito ergo sum (I think therefore I am) that separates the mind from the body and tends to make humans mechanistic, rather for the African there are no spate beings, you cannot exist without others (Forster 2010a). He cites Mudimbe who is summarizing Kagame thus:

In sum, the ntu is somehow a sign of a universal similitude. Its presence in beings brings them to life and attests to both their individual value and to the measure of their integration and dialectic of vital energy. "Ntu" is both a uniting and a differentiating vital norm which explains the powers of vital inequality in terms of difference between beings. It is a sign that God, father of all beings... has put a stamp on the universe, thus making it transparent in a hierarchy of sympathy. Upwards one would read the vitality which, from minerals through vegetables, animals, and humans, links stones to the departed and God himself. Downwards, it is a genealogical filiation of forms of beings, engendering or relating to one another, all of them witnessing to the original source that made them possible. (Forster 2010a, section 6)

Balcomb as cited by Forster interpreting the just mentioned quotation avers that: "The interconnectedness of the universe, beginning with the creator and going all the way down to rocks, can surely not be more strongly stated. Here is a system that is indeed a Cartesian nightmare and a Whiteheadian dream” (Forster 2010a). For Africans, Jacob Olupona states that: "All plants and animals and humans share the same divine energy, ase, they are all sacred and all related. Kinship is very important in African cultures, and the plants and the animals are kin. They are family” (Maguire 2000, 52).

\section{Towards Ecological Relationality}

What are the implications of the African idea of relationality to environmental wellbeing? The followings are some of the implications: (1) humans are part of nature and not separate from nature; (2) there is vital interaction between humans and nature; (3) human existence and survival depends on nature; and (4) nature is to be reverenced and protected. The reality that humans are part of nature is indisputable. While the earth can exist without humans, humans cannot exist without the earth. In almost all indigenous philosophies, the earth is considered a kin. Ejeh is right to note that: "Aside from the fact that the land is sacred, it is conceived of as a special gift from God that must be religiously guarded with respect and dignity (2008, 214-5). The human relationship to the earth is not like that of an animate to an inanimate thing. The earth is considered to be alive. In some African cosmology, the earth is called a mother that nourishes and feeds her children. The earth is not a thing. It is a being that has life of which humans are part and parcel. Among the Native Americans, they see themselves as part of the earth and it is to the earth they would return. This serious implication should not be overlooked for when humans begin to perceive the earth as simply a platform for their existence; the tendency 
is to abuse it.

The relationship of humans to the earth is a vital one then. This relationship is a carrier of life. Human life, at least in its material aspects, comes from mother earth. The earth-mother is the one that nourishes peoples. The human relationship to the earth is very vital and important. It cannot be over-emphasized. It is in the earth's environment that humans live their lives. As propounded by Ignacimuthu,

... environment is part and parcel of our life. It is interior to our experience of living. To live and act is to breathe the air, to drink some water, to eat fruits, roots, leaves, seeds, leaves, etc. We depend on minerals, plants, animals and these depend on the earth and the earth depends on a thousand cosmic, physical, chemical, and magnetic factors and forces, processes and interactions. $(2010,14)$

The earth is to be reverenced and protected. The various rituals among Africans and other indigenous people are aimed at reverencing the earth. Maguire citing Jacob Olupona is right to note that African idea of kinship makes Africans "call for enormous reverence for all that lives, even if tragically, we must kill some of life to live ourselves" $(2000,52)$. The recognition of the reality of intimate relatedness of humans to the earth or natural world in African cosmology has made many Africans in time past, seen in the earth a mother (ala). The earth is not to be harmed. It was believed that when you till or cultivate the earth, you are tilling the hair of your mother (Maguire 2000, 52) and so you are to use the earth with care. Because of this, you were to do it with ultimate care. Traditional Africans harvested and hunted with prudence and temperance. For instance in traditional practices, you were not to catch a mother bird or animal with the infant. That the African idea of relationality with nature helps in reverence for the earth shows in the fact that in many communities you do not go to the farm or fish in the streams everyday (Ikenna 2010, 70). There was no reckless destruction of trees in time past; no wonder many people in the Niger Delta in Nigeria are protesting against oil companies who destroy their sacred lands and build roads through their forests without any concern for sustainability (Ikenna 2010, 70).

It has been noted that one concept that is used to express the African notion of relationality or relationship is ubuntu. The implication of this ubuntu should never be overlooked. Behrens (2013) states forcefully that:

The emphasis on community, identifying with others and solidarity and caring, makes ubuntu a relational ethic that prizes harmonious relationships. This challenges Western bioethics, which focuses on individual autonomy and the rational application of abstract theories and moral principles to ethical issues. It also resonates with the ethics of care, highlighting the central importance of caring, emotion, and relationships in moral decision making. This philosophy echoes the call from other communitarian perspectives for bioethics to take the fact that we are embedded in communities and families more seriously. (2013, section 5)

When ubuntu is practiced, life is shared and people live prudently in making use of resources. Through ubuntu, consumerism and avarice is destroyed. Behrens propounds further that:

Thaddeus Metz, who has written prolifically on ubuntu, aims to develop it as a moral theory comparable with dominant Western moral theories such as deontology and utilitarianism. He characterizes ubuntu as entailing that "An action is right just insofar as it is a way of living harmoniously or prizing communal relationships, ones in which people identify with each other and exhibit solidarity with one another; otherwise an action is wrong”. For Metz, the key to this African ethic is harmonious relationships characterized by identifying with others (or conceiving of oneself as part of a group or community) and by solidarity (caring for one another and seeking the good of others). (2013, section 5) 


\section{Conclusion}

This paper does not in any way imply that recognition of human relationality to the earth is the only panacea to the ecological crisis. No one solution or idea can solve the ecological crisis. But various ideas and solutions have to be combined. One idea that can never be neglected in the search for solutions is the principle of relationality. The recognition of human inter-relationality with the earth and all things is not for its own sake. It leads to a practical life of relating and working to enhance the wellbeing of what you are related with. Though Africans like other people may have carried out practices and other activities that have wounded the earth, that is not the focus of this work. The focus is that African belief on relationality has helped and can help in protecting the earth and mitigating harmful human practices that degrades and devalues the earth. By recognizing this value of human relationality with the earth, a better human-earth relationship will be cultivated.

\section{Works Cited}

Achebe, Chinua. Things Fall Apart. London: Heinemann Educational Books, 1958.

Bellamy, Patrick. Academic's Dictionary of Environment. New Delhi: Academic India Publishers, 2007.

Behrens, K. G. “Towards an Indigenous African Bioethics.” The South African Journal of Bioethics and Law 6.1 (2013). $<$ http://www.sajbl.org.za/index.php/sajbl/article/view/255/289>.

Berry, Thomas. The Dream of the Earth. San Francisco: Sierra Book Club, 1988.

Coates, Peter. Nature: Western Attitudes since Ancient Times. Cambridge: Polity Press, 1998.

Dukor, Maduabuchi. Scientific Paradigm in African Philosophy: Theistic Panpsychic Epistemology and Ontology. Saarbrucken: Lap Lambert Academic Publishing, 2010.

Ehusani, George Omaku. An Afro-Christian Vision (Ozovehe): Towards a More Humanized World. Lanham: University Press of America, 1991.

Ejeh, Ameh. Scientific Evolution, Creation Theologies and African Cosmologies in Dialogue: Towards a Christian Theology of Evolution. Bloomington: Xlibris Corporation, 2008.

Forster, Dion. “African Relational Ontology, Individual Identity, and Christian Theology: An African Theological Contribution Towards an Integrated Relational Ontological Identity.” Theology $113.874 \quad$ (2010): 243-53. $<$ http://tjx.sagepub.com/content/113/874/243.abstract>.

---. “A Generous Ontology: Identity as a Process of Intersubjective Discovery: An African Theological Contribution.” Theological Studies 66 (2010a). <http://www.hts.org.za/index.php/HTS/article/view/731/1132>.

Ignacimuthu, S. Environmental Spirituality. Bombay: St. Paul Society, 2010.

Ikeke, Mark Omorovie. “'Kami’ and African Panpsychism: An Ecophilosophical Appraisal.” Perspectives in the Arts and Humanities 4.1 (2014). <http://journals.ateneo.edu/ojs/apah/article/view/1830>.

---. Redesigning an Ecosolidarity and Indigenously-Informed Education. Ann Arbor: Pro quest UMI Dissertation Services, 2004.

Ikenna, Bonaventure. "A Spirit-Based Theology of the Environment: Lessons from African and Christian Traditions.” African Journal of Contextual Theology 2 (2010): 61-80.

Mackenzie, Aulay, Andy S Ball, and Sonia R Virdee. Intsant Notes in Ecology. Oxford: BIOS Scientific Publishers Limited, 1998.

Maguire, Daniel. Sacred Energies: When the World Religions Sit down to Talk about the Future of Human Life and the Plight of the Planet. Minneapolis: Fortress Press, 2000.

Oborji, Francis Anekwe. Towards a Christian Theology of African Religion: Issues of Interpretation and Mission. Eldoret: Amecea Garba Publication, 2005.

Oxford University Press. The Oxford Advanced Learner's Dictionary. 2014. <http://www.oxforddictionaries.com/definition/ english/relate>.

Turaki, Yusufu. Foundations of African Traditional Religion and Worldview. Nairobi: WorldAlive Publishers Limited, 2006.

White, Lynn, Jr. “The Historical Roots of Our Ecological Crisis.” Science New Series 155.3767 (1967): 1203-7. $<$ http://www.sciencemag.org/content/155/3767/1203.citation>.

Vantassel, Stephen. Dominion over Wildlife: An Environmental Theology of Human-Wildlife Relations. Eugene: Resources Publication, 2009. 